\title{
Suicidality Protective Factors for African American Adolescents: A Systematic Review of the Research Literature
}

\author{
Jocelyn R. Droege ${ }^{1^{*}}$, W. LaVome Robinson ${ }^{2}$, Leonard A. Jason ${ }^{1}$ \\ ${ }^{1}$ Center for Community Research, DePaul University, Chicago, IL 60614 \\ ${ }^{2}$ Department of Psychology, DePaul University, Chicago, IL 60614
}

Received: April 26, 2017; Accepted: : May 25, 2017; Published: May 31, 2017

*Corresponding author: Jocelyn R. Droege, Center for Community Research, DePaul University, 990 W. Fullerton Avenue, Suite 3100, Chicago, IL 60614. E-mail: jdroege@depaul.edu

\begin{abstract}
Overall rates of African American adolescent suicide have been increasing for the past 50 years; however, the research literature examining factors related to suicide for these vulnerable youth is sparse. The shortage of research literature on suicidality protective factors is particularly significant. Little is known about the impact of protective factors on African American youth, especially within subgroups (e.g., gender and socioeconomic status). Approximately $40 \%$ of African American youth live in poverty, exposing them to contextual stressors that place them at increased risk for suicidality. Females are significantly more likely to have suicidal ideation and make attempts, whereas males surpass females in their rates of completions. To better understand suicidality protective factors, we conducted a systematic review of the research literature on protective factors for African American adolescents, with a focus on gender differences and urban, low-income youth. This review yielded 26 articles that met inclusion criteria and identified protective factors in the following categories: familial, religiosity-based, relational/social, personal, and socioecological. Gender differences and protective factors for urban, low-income youth are discussed, regarding their role in the prevention of suicidality. This review highlights a need for further research to identify and clarify suicidality protective factors for African American adolescents.
\end{abstract}

Keywords: Suicide; Suicidality; African American Adolescents; Protective Factors; Resiliency

\section{Background}

Suicidality is an ever-prevalent threat against the lives of many adolescents. Approximately 157,000 youth, between the ages of 10 and 24, receive medical attention for injuries sustained through intentional self-harm [6]. Completed suicides comprise the third leading cause of death among U.S. youth, 10-14 years of age, and the second leading cause of death among U.S. youth, 15-24 years of age [5]. Suicidality is a multi-faceted construct that encompasses a variety of suicidal thoughts and behaviors including suicidal ideation, plans, attempts, and completions $[45,49]$. Suicidality is prevalent among U.S. adolescents at rates that vary by factors such as race/ethnicity (e.g., African Americans versus European Americans) and gender [7].

Historically, rates of suicide among African American adolescents have been relatively low when compared to those of European American adolescents [46]. However, overall rates of African American suicide have been on the rise since 1965 [32,52]. More recent reports from the $\mathrm{CDC}$ indicate rates of suicidality among African American adolescents have been nearing and/ or surpassing those of European American adolescents. For example, according to the CDC's 2013 Youth Risk Behavior Surveillance Survey (YRBSS), African American youth in grades 9-12 were significantly more likely to report suicide attempts within the 12 months prior to the survey than their European American counterparts [7].

African American youth live in poverty at twice the rate of European American youth. With nearly 40\% of African American adolescents living in poverty, this vulnerable population is more likely to live in under-resourced neighborhoods and be exposed to more community violence $[56,46]$. In a predominantly African American (92\%) sample of urban youth, 90\% witnessed violence or were victimized in the year prior to data collection, and $77 \%$ were exposed to more than one instance of community violence. Other factors related to poverty, such as hopelessness, increased substance use, residential mobility, family dysfunction, and mental health problems (e.g., depression) are also associated with suicidality $[10,16,19,20,28,29,51]$. Mood disorders, such as depression and dysthymia among African Americans have been identified as some of the psychiatric risk factors most often predictive of suicidal behaviors [31,53,25]. Further, African American adolescents face barriers to mental health treatment, such as lack of insurance and access to high-quality services, and cost of medical expenses and transportation [51]. As such, they are significantly less likely to receive treatment for mental health problems than European American adolescents [43]. African American adolescents, subjected to the treatment barriers and contextual stressors of living in disadvantaged, urban communities, are twice as likely to experience suicidal ideation, and four times as likely to attempt suicide as their European American counterparts [13]. Results from the Mobile Youth Survey, a large, multi-cohort, longitudinal study, indicated that an alarming $36 \%$ of extremely impoverished African American adolescents would attempt suicide by the age of 19 [15]. With 
African American adolescents grossly overrepresented in underresourced, urban communities, they are at high risk for suicidality related to their disadvantaged environment, and in great need of culturally-relevant sources of protection.

\section{Gender Differences}

The CDC's Youth Risk Behavior Surveillance Survey identified a number of gender differences associated with suicidality among African American adolescents. For example, African American girls endorsed suicidal ideation and plans at significantly higher rates than their male counterparts (i.e., seriously considered attempting suicide, 22.4 vs. $11.6 \%$; made a plan about how they would attempt suicide, 16.9 vs. $10.3 \%$ ) [7]. Additionally, African American female adolescents have demonstrated a three-time greater likelihood of attempting suicide than males [31]. African American male adolescents, 1024 years old, however, had significantly higher rates of suicide completion than African American females (8.26 versus 1.83, respectively) [5]. Gender differences in rates of suicidality may be indicative of differential exposure to risk, availability of resources, lethality of methods, and responses toward factors that mitigate suicidality risk in African American adolescents [22,57]. Gender differences in risk and protective factors for suicidality may have implications on suicide-prevention programs, treatment, and interventions. Despite the need for further understanding of gender differences in African American suicidality, there is a dearth of literature that explores gender differences, particularly among minority cultures [37].

\section{Previous Research}

Research, historically, has focused more on European American, or majority youth suicidality over African American suicidality $[16,37,46]$. Further, more published research is available on risk factors of African American youth suicidality than on protective factors, thus emphasizing a more negative perspective with this population, rather than the more resiliencybased framework of protective factors [11]. Identifying protective factors that may attenuate suicide risk behavior for African American youth remains understudied [21,22]. There is an additional dearth of literature that examines sub-groups of African Americans, in order to identify the cultural factors that buffer against suicide risk among African American youth of different age groups, gender, regions, socioeconomic status, and ethnocultural backgrounds [57].

Reviews of the existing literature on African American suicidality have tended to focus more heavily on risk factors and general African American populations. One published study reviewed literature that examined ethnocultural risk factors of youth suicidality (with a partial focus on African American youth); while another examined suicide prevention and treatment across ethnic groups, with a minor emphasis on risk factors and mention of only one protective factor for African American youth [9,21]. Chu and colleagues conducted an extensive review of suicide literature pertaining to four cultural minority groups, including African Americans; however, reported only minimal findings on African American adolescent suicidality protective factors [8]. Gould and colleagues conducted a literature review of youth suicide risk factors and prevention interventions; however, they did mention one protective factor for African American youth suicidality [23]. Three literature reviews examined risk and protective factors of suicidality among African Americans in general, with no specification of age, location, or socioeconomic status $[32,57,63]$. Another review paper addressed risk and protective factors of suicidality among African American youth, adults, and elderly. Protective factors were more generalized (i.e., not tailored to youth) and there was no specific mention of socioeconomic status of the samples in the reviewed studies [18]. Crosby and Molock conducted a review of the history of suicide research in African American communities, which included predominantly risk factor literature, with some focus on protective factors for adolescent suicide [11]. Balis and Postolache conducted a literature review of risk and protective factors across five ethnic groups of adolescents, including African Americans [1]. However, much of the literature reviewed by Balis and Postolache pertained to older or age-unspecified African American populations. Another literature review focused on risk and, to a lesser extent, protective factors for adolescent suicide, and gender differences, across four ethnic groups, including African Americans [37]. Joe reviewed literature on national suicide trends of African American youth, with an emphasis on explanatory hypotheses and practice implications, and, to a much lesser extent, risk and protective factors for African American youth suicide [30]. To date, no known literature reviews have been published that have a primary focus on sociocultural protective factors associated with African American youth suicidality. Nor have any review papers been identified that attempt to emphasize low-income, urban, African American adolescents, a sub-group of African Americans who are particularly at risk for suicidality. There is a gap in the research literature that needs to be filled in order to inform future policies, programs, prevention interventions, and treatment.

\section{Aims of Review}

Given the need for further exploration of protective factors for African American adolescent suicidality, a systematic review was conducted in response to the primary research questions: What factors attenuate suicidality among African American adolescents? Can protective factors for African American adolescent suicidality be organized categorically, in a theoretically-based manner? Additionally, this review addressed the following secondary research questions: What factors attenuate suicidality among low-income, urban, African American adolescents? Do gender differences exist among African American adolescents regarding factors that attenuate suicidality?

\section{Method}

\section{Search Strategy}

An electronic literature search of peer-reviewed articles was conducted utilizing the following online databases: PsycInfo, EBSCOhost, Google Scholar, and PubMed. Databases were searched for relevant articles up to January, 2015. In order to identify as many relevant studies as possible, references from 
relevant articles were also reviewed. Search terms used included African American AND/OR adolescent AND suicide OR suicidality OR suicidal AND/OR protective OR resiliency OR mitigating AND/ OR factors. Additional search terms included the previous terms, as well as low-income OR urban.

\section{Inclusion Criteria}

Included articles were selected from peer-reviewed, English-language journals. Only articles addressing full or partial samples of African American adolescents were included in the review study. The World Health Organization defines adolescence as individuals 10-19 years of age; however, there is no agreedupon adolescent age range [65]. Studies have identified the upper threshold of adolescence as ranging between 18 and 25 [27]. For the purposes of this study, adolescence was defined as anyone between the ages of 10 and 24, as suicide rates are highest for this age group among African Americans [5]. Thus, included articles consisted of studies involving samples of African American youth between the ages of 10 and 24. In order to obtain the largest number of articles to be reviewed, samples whose upper-age range exceeded 24 , but whose average age fell within the age range of 10-24, were included in the present study.

\section{Results}

The search strategy yielded 26 articles that met the inclusion criteria. All identified studies examined protective factors for African American adolescent suicidality. Of the 26 articles identified by the search, only five utilized data from samples of urban and/or low-income African American adolescents. The 21studies that examined data from samples not specified as urban or low-income are summarized in (Table 1). Studies that utilized urban and/or low-income African American adolescent samples are summarized in (Table 2). Articles are summarized by description of the sample, protective factors, and gender differences associated with the protective factors.

\begin{tabular}{|c|c|c|c|c|}
\hline Citation & Sample & Age/Grade in School & Protective Factors & Gender Differences \\
\hline $\begin{array}{c}\text { Bearman \& } \\
\text { Moody, } 2004\end{array}$ & $\begin{array}{c}\text { Add Health U.S. representative }(N= \\
\text { 13,465; } 61 \% \text { Caucasian, } 25 \% \text { Other } \\
\text { (i.e., Native American, Asian, Hispanic, } \\
\text { mixed-race/ethnicity), } 14 \% \text { African } \\
\text { American) }\end{array}$ & $\begin{array}{l}\text { Ages 11-21; Grades } \\
7-12\end{array}$ & $\begin{array}{l}\text { Dense school social network } \\
\text { linking adolescents together } \\
\text { (F - SI; M - SA); Transitive } \\
\text { relationships (F - SI); High self- } \\
\quad \text { esteem (M/F - SI, F - SA) }\end{array}$ & Yes \\
\hline $\begin{array}{c}\text { Borowsky, } \\
\text { Ireland, \& } \\
\text { Resnick, 2001 }\end{array}$ & $\begin{array}{c}\text { Add Health U.S. representative } \\
(N=13,110 ; \text { Caucasian, African } \\
\text { American, Hispanic }\end{array}$ & Grades 7-12 & $\begin{array}{l}\text { Parent-Family Connectedness; } \\
\text { Emotional Well-Being (F); } \\
\text { Academic Achievement/Grade } \\
\text { Point Average (M) }\end{array}$ & Yes \\
\hline $\begin{array}{c}\text { Burr, Hartman, } \\
\text { \& Matteson, } \\
1999\end{array}$ & $\begin{array}{l}\text { African American males (range of } \\
\text { SES backgrounds, from those "living } \\
\text { below the official poverty line" } \\
\text { to those with "upper white-class } \\
\text { occupations") }\end{array}$ & $\begin{array}{c}\text { Ages 15-24 } \\
\text { (comparison group, } \\
\text { "all black males" } 15 \\
\text { and over) }\end{array}$ & $\begin{array}{l}\text { Increased socioeconomic status } \\
\text { (i.e., income/occupation) }\end{array}$ & Not assessed \\
\hline $\begin{array}{l}\text { Davidson, } \\
\text { Wingate, Slish, } \\
\text { \& Rasmussen, } \\
2010\end{array}$ & $\begin{array}{l}\text { African American college students ( } N \\
\quad=115 ; 78 \text { female, } 37 \text { male) }\end{array}$ & $\begin{array}{l}\text { Ages 18-31 }\left(M_{\text {Age }}=\right. \\
20.37 \text { years }) \text {; College } \\
\text { freshmen through } \\
\text { seniors }\end{array}$ & Hope & Not indicated \\
\hline $\begin{array}{l}\text { Gangwisch, et } \\
\text { al., } 2010\end{array}$ & $\begin{array}{l}\text { Add Health U.S. representative }(N= \\
\qquad 15,659)\end{array}$ & $\begin{array}{l}\text { Ages 12-21; Grades } \\
7-12\end{array}$ & $\begin{array}{l}\text { Earlier parental set bedtime } \\
\text { (i.e., 10:00 p.m. or earlier) }\end{array}$ & Not indicated \\
\hline $\begin{array}{c}\text { Greening \& } \\
\text { Stoppelbein, } \\
2002\end{array}$ & $\begin{array}{c}\text { Caucasian }(72 \%) \text { and African } \\
\text { American (28\%) adolescents }(N= \\
1,098 ; 53 \% \text { female, } 47 \% \text { male })\end{array}$ & Ages $14-18$ & $\begin{array}{l}\text { Orthodoxy; Family support; } \\
\text { Ascribing to an adaptive } \\
\text { attributional style }\end{array}$ & No \\
\hline
\end{tabular}




\begin{tabular}{|c|c|c|c|c|}
\hline $\begin{array}{c}\text { Harris \& } \\
\text { Molock, } 2000\end{array}$ & $\begin{array}{c}\text { African American adolescents } \\
\text { from "middle to upper-middle } \\
\text { socioeconomic backgrounds" ( } N= \\
\text { 188; } 67 \% \text { female, } 32.4 \% \text { male) }\end{array}$ & $\begin{array}{l}\text { Ages 17-22; College } \\
\text { freshmen and } \\
\text { sophomores }\end{array}$ & $\begin{array}{l}\text { Family cohesion; Family } \\
\text { support }\end{array}$ & Not indicated \\
\hline $\begin{array}{l}\text { Haynie, South, \& } \\
\text { Bose, } 2006\end{array}$ & $\begin{array}{l}\text { Add Health U.S. representative }(N= \\
\text { 9,594; 68\% Caucasian, } 16 \% \text { African } \\
\text { American, } 17 \% \text { other race; } 52.4 \% \\
\text { female, } 47.6 \% \text { male; } 8 \% \text { received } \\
\text { public assistance) }\end{array}$ & $\begin{array}{c}\text { Ages 11-20; Grades } \\
7-12\end{array}$ & $\begin{array}{l}\text { Living in current residence } \\
\text { for more than two years (F); } \\
\text { High quality relationships with } \\
\text { parents (F); Older age (F); } \\
\text { Having popular friends (i.e., } \\
\text { adolescent's friends received } \\
\text { many friendship nominations; } \\
\text { F); School attachment (F) }\end{array}$ & Yes \\
\hline $\begin{array}{l}\text { Joe, Baser, } \\
\text { Neighbors, } \\
\text { Caldwell, \& } \\
\text { Jackson, } 2009\end{array}$ & $\begin{array}{l}\text { National Survey of American Life } \\
\text { nationwide sample of African } \\
\text { American (69.2\%) and Caribbean } \\
\text { Black (30.8\%) adolescents ( } N=1,170 \text {; } \\
\quad 52 \% \text { female, } 48 \% \text { male) }\end{array}$ & $\begin{array}{c}\text { Ages } 13-17\left(M_{A g e}=15\right. \\
\text { years, } S D=1.42)\end{array}$ & $\begin{array}{l}\text { Living in southern or western } \\
\text { regions of the U.S. (compared } \\
\text { to northeastern regions) }\end{array}$ & Not indicated \\
\hline Kidd, et al., 2006 & $\begin{array}{c}\text { Add Health U.S. representative }(N \\
=9,142 ; 70.1 \% \text { Caucasian, } 20.1 \% \\
\text { African American, } 12 \% \text { Hispanic, } \\
\text { 6.6\% "other," } 4.5 \% \text { Asian, 3.7\% } \\
\text { Native American; } 52 \% \text { female, } 48 \% \\
\text { male) }\end{array}$ & Grades 7-11 & $\begin{array}{l}\text { Parent-family connectedness; } \\
\text { Peer connectedness (M with } \\
\text { history of attempts); School } \\
\text { connectedness (M with history } \\
\text { of attempts) }\end{array}$ & Yes \\
\hline $\begin{array}{c}\text { Kimbrough, } \\
\text { Molock, \& } \\
\text { Walton, } 1996\end{array}$ & $\begin{array}{l}\text { African American college students } \\
\text { from "middle- or upper-class } \\
\text { socioeconomic status" }(N=157 \text {; } \\
71.1 \% \text { female, } 28.9 \% \text { male })\end{array}$ & $\begin{array}{c}\text { Ages } 17-46\left(M_{\text {Age }}=\right. \\
19.9 \text { years); College } \\
\text { freshmen }(64.3 \%) \text {, } \\
\text { sophomores }(17.3 \% \text {, } \\
\text { juniors }(12.2 \%) \text {, and } \\
\text { seniors }(6.1 \%)\end{array}$ & $\begin{array}{l}\text { Perceived social support (i.e., } \\
\text { family, platonic friends, and } \\
\text { boyfriend/girlfriends) }\end{array}$ & Not indicated \\
\hline $\begin{array}{l}\text { Maimon, } \\
\text { Browning, \& } \\
\text { Brooks-Gunn, } \\
2010\end{array}$ & $\begin{array}{c}\text { Urban adolescents }(N=990 ; \\
7 \text { categories of racial/ethnic } \\
\text { composition; high, medium, and } \\
\text { low SES; } 50 \% \text { female, } 50 \% \text { male })\end{array}$ & $\begin{array}{c}\text { Ages } 11-16\left(M_{\text {AgeW1 }}=\right. \\
14 \text { years, } M_{\text {AgeW2 }}=15.5 \\
\text { years })\end{array}$ & $\begin{array}{l}\text { Family attachment and } \\
\text { support; Collective efficacy } \\
\text { interacts positively with family } \\
\text { attachment and support to } \\
\text { reduce likelihood of SA; Longer } \\
\text { durations of time living in one } \\
\text { residency (SA) }\end{array}$ & Not assessed \\
\hline
\end{tabular}




\begin{tabular}{|c|c|c|c|c|}
\hline $\begin{array}{l}\text { Marion \& Range, } \\
2003\end{array}$ & $\begin{array}{l}\text { African American female college } \\
\text { students from rural }(73.3 \%) \text { and } \\
\text { urban }(26.7 \%) \text { southeastern } \\
\text { universities }(N=300)\end{array}$ & $\begin{aligned} M_{\text {Age }}= & 22.09 \text { years, } S D \\
= & 5.07\end{aligned}$ & $\begin{array}{l}\text { Family social support; } \\
\text { Collaborative religious problem } \\
\text { solving (i.e., "God and I work } \\
\text { together as partners" to solve a } \\
\text { problem); Negative attitude } \\
\text { toward suicide acceptability }\end{array}$ & Not applicable \\
\hline $\begin{array}{l}\text { Matlin, Molock, } \\
\text { \& Tebes, } 2011\end{array}$ & $\begin{array}{c}\text { "Middle class" African American } \\
\text { adolescents }(N=212 ; 62.7 \% \text { females, } \\
37.3 \% \text { males })\end{array}$ & $\begin{array}{c}\text { Ages 13-19; Grades } \\
9-10\end{array}$ & $\begin{array}{l}\text { Family support; Peer support; } \\
\text { Community connectedness }\end{array}$ & Not indicated \\
\hline $\begin{array}{l}\text { McKeown, et al., } \\
1998\end{array}$ & $\begin{array}{c}\text { Suburban South Carolina middle } \\
\text { and high school students }(N=359 ; \\
\text { weighted } \\
\text { percentages: } 15.7 \% \text { African } \\
\text { American, } 84.4 \% \text { Caucasian; } 56.0 \% \\
\text { female, } 44.0 \% \text { male; } 70.6 \% \text { middle- } \\
\text { high SES, } 29.4 \% \text { low SES) }\end{array}$ & $\begin{array}{c}\text { Ages } \leq 12(28.6 \%), 13 \\
(37.8 \%, 14(28.6 \%), \geq \\
15(5.0 \%)\end{array}$ & Family cohesion & No \\
\hline $\begin{array}{c}\text { Perkins \& } \\
\text { Hartless, } 2002\end{array}$ & $\begin{array}{c}\text { African American (26.1\%) and } \\
\text { European American (73.9\%) } \\
\text { adolescent residents of Michigan ( } N \\
=14,922 ; 53 \% \text { female, } 46.7 \% \text { male; } \\
\text { 45.5\% rural, } 41.6 \% \text { urban, } 12.9 \% \\
\text { suburban) }\end{array}$ & $\begin{array}{c}\text { Ages 12-17; } \\
\text { Predominantly grades } \\
\text { 7, 9, and } 11\end{array}$ & $\begin{array}{l}\text { Family support (F - SI, M/F } \\
\text {-SA); Older age (M/F - SI); } \\
\text { School climate (M - SI, M/F } \\
\text {-SA) }\end{array}$ & Yes \\
\hline $\begin{array}{c}\text { Resnick, et al., } \\
1997\end{array}$ & $\begin{array}{l}\text { Add Health U.S. representative ( } N \\
=11,572[\mathrm{~W} 1] \text {; Caucasian, African } \\
\text { American, Hispanic, Asian/Pacific } \\
\text { Islander, Native American, "other" } \\
\text { mixed race/ethnicity) }\end{array}$ & Grades 7-12 & $\begin{array}{l}\text { Parent-family connectedness; } \\
\text { School connectedness }\end{array}$ & Not indicated \\
\hline $\begin{array}{c}\text { Walker \& } \\
\text { Bishop, } 2005\end{array}$ & $\begin{array}{l}\text { African American college students ( } N \\
=459 ; 64 \% \text { African American, } 35 \% \\
\text { Caucasian; } 65 \% \text { female, } 33.5 \% \text { male) }\end{array}$ & $\begin{array}{c}\text { Ages } 18-41\left(M_{\text {Age }}=\right. \\
20.88 \text { years })\end{array}$ & $\begin{array}{c}\text { Intrinsic religiosity; Social } \\
\text { support }\end{array}$ & Not indicated \\
\hline $\begin{array}{l}\text { Wang, Lightsey, } \\
\text { Pietruszka, } \\
\text { Uruk, \& Wells, } \\
2007\end{array}$ & $\begin{array}{c}\text { College students }(N=416 ; 48 \% \\
\text { Caucasian, } 45 \% \text { African American, 7\% } \\
\text { Hispanic/Latino, American Indian/ } \\
\text { Alaskan Native, Asian American, } \\
\text { other, or biracial; } 73 \% \text { female, } 27 \% \\
\text { male) }\end{array}$ & $\begin{array}{c}M_{A g e}=19.77 \text { years, } \\
S D=4.6 ; \text { College } \\
\text { freshmen }(81 \%)\end{array}$ & $\begin{array}{l}\text { Reasons for living; Avoidance- } \\
\text { oriented coping (indirect } \\
\text { effect on SI/SA via positive } \\
\text { relationship with reasons for } \\
\text { living); Purpose in life (indirect } \\
\text { effect on SI/SA via inverse } \\
\text { relationship with depression) }\end{array}$ & Not indicated \\
\hline
\end{tabular}




\begin{tabular}{|c|c|c|c|c|}
\hline $\begin{array}{c}\text { Wang, Lightsey, } \\
\text { Tran, \& } \\
\text { Bonaparte, } \\
2013\end{array}$ & $\begin{array}{l}\text { African American college student }(N= \\
\qquad 341 ; 73 \% \text { female, } 27 \% \text { male })\end{array}$ & $\begin{array}{c}M_{\text {Age }}=21.56 \text { years, } \\
\qquad S D=5.70 ; \text { College } \\
\text { freshmen }(36.4 \%) \text { and } \\
\text { sophomores }(22.3 \%) \\
\text { made up largest } \\
\text { proportion of students }\end{array}$ & $\begin{array}{l}\text { Reasons for living (F); Life } \\
\text { satisfaction (M) }\end{array}$ & Yes \\
\hline $\begin{array}{l}\text { Wang, Nyutu, \& } \\
\text { Tran, } 2012\end{array}$ & $\begin{array}{l}\text { African American college students ( } N \\
\quad=361 ; 72 \% \text { female, } 28 \% \text { male) }\end{array}$ & $\begin{array}{c}M_{\text {Age }}=21.6 \text { years, } S D \\
=5.8\end{array}$ & $\begin{array}{l}\text { Reasons for living; Avoidance- } \\
\text { oriented coping }\end{array}$ & Not indicated \\
\hline \multicolumn{5}{|c|}{$\begin{array}{l}\mathrm{F}=\text { female } ; \mathrm{M}=\text { male } \\
\mathrm{SI}=\text { suicidal ideation; } \mathrm{SA}=\text { suicide attempt }\end{array}$} \\
\hline
\end{tabular}

Table 2 :Summary of Studies Investigating Protective Factors for Suicidality among Low-Income, Urban, African American Adolescents

\begin{tabular}{|c|c|c|c|c|}
\hline Citation & Sample & Age/Grade in School & Protective Factors & Gender Differences \\
\hline $\begin{array}{l}\text { Farrell, Bolland, \& } \\
\text { Cockerham, } 2014\end{array}$ & $\begin{array}{l}\text { Mobile Youth Survey } \\
\text { "Extremely impoverished" } \\
\text { African American } \\
\text { adolescents }\left(N=7,299 ; M_{\text {Sex }}\right. \\
\quad=49.1 \% \text { female })\end{array}$ & $\begin{array}{c}\text { Ages } 9.75-19.25\left(M_{A g e}=\right. \\
12.1 \text { years })\end{array}$ & Peer support; Younger age & No \\
\hline $\begin{array}{l}\text { Fitzpatrick, Piko, \& } \\
\text { Miller, } 2008\end{array}$ & $\begin{array}{c}\text { Urban African American } \\
\text { adolescents }(N=1,526 ; \\
50.2 \% \text { female })\end{array}$ & $\begin{array}{c}\text { Grades 5-6 (40.1\%), 7-8 } \\
(26.4 \%), 9-12(33.5 \%)\end{array}$ & $\begin{array}{l}\text { Self-esteem; Perceived spiritual } \\
\text { community membership }\end{array}$ & Not indicated \\
\hline $\begin{array}{c}\text { Gutierrez, } \\
\text { Muehlenkamp, } \\
\text { Konick, \& Osman, } \\
2005\end{array}$ & $\begin{array}{l}\text { Urban adolescents }(N=337 ; \\
51.9 \% \text { Caucasian, } 24.6 \% \\
\text { African American, } 7.1 \% \\
\text { Latino/a, 3.6\% Asian, } 12.8 \% \\
\text { unidentified; } 199 \text { females, } \\
138 \text { males) }\end{array}$ & Ages 13-19; Grades & Reasons for living & Not assessed \\
\hline $\begin{array}{c}\text { O'Donnell, } \\
\text { 0'Donnell, Wardlaw, } \\
\text { \& Stueve, } 2004\end{array}$ & $\begin{array}{l}\text { Urban adolescents }(N=879 ; \\
\text { 68.6\% African American, } \\
\text { 16.5\% Hispanic/Latino, } \\
\text { 8.1\% other, } 6.8 \% \text { African } \\
\text { American and Hispanic; } \\
\text { 57.9\% female, } 42.1 \% \text { male) }\end{array}$ & Ages 16-17; Grade 11 & $\begin{array}{l}\text { Family closeness; Having lived } \\
\text { in the same neighborhood for }>5 \\
\text { years; Religiosity }\end{array}$ & No \\
\hline $\begin{array}{l}\text { O'Donnell, Stueve, } \\
\text { Wardlaw, \& } \\
\text { O'Donnell, 2003 }\end{array}$ & $\begin{array}{c}\text { Urban adolescents }(N=879 ; \\
\text { 68.6\% African American, } \\
\text { 16.5\% Hispanic/Latino, } \\
\text { 8.1\% other, 6.8\% African } \\
\text { American and Hispanic; } \\
57.9 \% \text { female, } 42.1 \% \\
\text { male) }\end{array}$ & Ages 16-17; Grade 11 & $\begin{array}{l}\text { Perceived support (F-SI); } \\
\text { Family network availability; } \\
\text { Accessing a formal network }\end{array}$ & Yes \\
\hline $\mathrm{F}=$ female & & & & \\
\hline
\end{tabular}




\section{Theoretical Framework For Protective Factors For Suicidality}

Emile Durkheim's sociological theory of suicide is often cited in literature, particularly when suicide among African American populations was the topic of interest $[14,16,39,54,62,64]$. Durkheim's theory is based on the notion that societal flux and dysregulation, and a greater divide between prosperity and poverty, brought on by modernization, led to a deterioration of traditionally supportive social bonds [14]. Community, marital, and parent-child bonds, as well as religious ties, strengthened the extent to which individuals were socially integrated into society. Social integration was the process by which individuals, through attachment to social groups, came together as a cohesive, community, bound by collective moral and societal norms. Industrialization of urban areas brought about a need to adapt and restructure to the changing times. The need to break ties with families and communities, in order to adapt to the rapidly transitioning and stressful period of modernization, grew and led to a breakdown of social integration. This deterioration of social integration, cohesion, and support coincided with increased rates of suicide [14]. Thus, Durkheim purported that social integration and cohesion were protective against suicide [14].

\section{Protective Factors for African American Adoles- cent Suicidality}

Durkheim's theory of social integration has been used to explain some of the protective factors for African American adolescent suicidality $[14,4,16,62]$. As previously noted, African American adolescents are more likely to live in low-income, under-resourced areas, and are at increased risk of neighborhood and family instability and dysregulation $[10,36,55]$. To further illustrate the point, Summerville and colleagues found that $67 \%$ of low-income African American adolescent suicide attempters reported family dysfunction (i.e., maladaptive family cohesion and/ or adaptability) [55]. Based on Durkheim's theory, a lack of stable familial and community bonds may, thus, put African American adolescents at increased risk of social disintegration and subsequent suicide [14]. According to Durkheim, social, familial, and religious factors promote social integration and cohesion, and mitigate suicidality. The present study identified several protective factors, many of which may be explained, categorically, by Durkheim's theory of social integration. Refer to (Table 1) and (Table 2) for a breakdown of protective factors by study.

\section{Familial Factors}

Familial bonds were identified by Durkheim as a route through which individuals may become more socially integrated and less at-risk for suicide [14]. Thirteen studies reported on familial protective factors for African American adolescents [3,15-17,23,24,26,28,34,39-42,46-48,50]. Among African American adolescents, parent and/or family cohesiveness, connectedness, closeness, attachment, support, and network availability were identified as protective factors for suicidality. Additionally, high quality relationships with parents were protective, as well as earlier parental set bedtimes. Two studies found that family cohesion was protective against suicide attempt and suicidal ide- ation $[9,26]$. No gender differences were found [42]. Three studies identified parent-family connectedness as protective against suicide attempts $[3,34,50]$. No gender differences were found [34]. O'Donnell and colleagues found family closeness to be a protective factor for urban African American youth suicidality [46]. Family attachment and support (i.e., emotional and social support provided by family) were identified by Maimon and colleagues as protective against suicide attempt [39]. Five additional studies found family support to be protective $[23,26,40,41,48]$. Although there were no gender differences for family support as a protective factor for suicide attempt, one study found family support to be protective against suicidal ideation for females only, when compared to their male counterparts whereas other studies found no gender differences for family support [48,23,26,39,41]. O'Donnell and colleagues found family network availability to be protective against suicide attempts; however, family network availability was not protective against suicide ideation for urban African American male adolescents [47]. Gangwisch and colleagues identified earlier parental set bedtimes (10:00 p.m. or earlier) as protective against suicidal ideation among African American adolescents [17]. Lastly, high quality relationships with parents provided protection against African American adolescent suicidality [28]. With approximately half of the studies selected for review reporting on the protective nature of familial factors, there seems to be a fairly well-supported association between feeling connected to a cohesive and supportive family, and protection against suicidality for both female and male African American adolescents.

For African American adolescents from a variety of socioeconomic backgrounds and regions, the familial protective component of Durkheim's theory was supported by the overall results of the present study. However, of the five studies that reported on the protective nature of familial factors for low-income, African American adolescents only two identified familial factors as significant protective factors for suicidality $[15,16,24,46,47]$. Familial factors reported as non-protective against suicidality among urban African American youth were parental involvement, supervision, support, warmth, family alliance $[15,16,24]$. Of the eight studies that identified familial protective factors for African American youth with various socioeconomic backgrounds, three found non-significant familial protective factors (i.e., parental social capital, monitoring, education, family structure); although, each study also identified alternative significant protective familial factors $[28,42,48]$. Family structure (i.e., composition) did not impact suicidality for African American youth of any socioeconomic background. Overall, familial factors were less protective for urban, low-income adolescents than for youth of various socioeconomic backgrounds.

\section{Religiosity-Based Factors}

Social Integration Theory explained that the protective nature of religious involvement resulted from one's involvement in religion comprised of shared beliefs, practices, and traditions, as an effective means of facilitating one's integration into society [14]. A total of seven studies reported findings on the protective nature of religiosity, five of which supported the notion of religi- 
osity-based factors as effective sources of protection against suicidality for African American youth [4,16,23,40,48,58,60]. Orthodoxy, intrinsic religiosity, collaborative religious problem solving, religious awareness (with increased reasons for living), and perceived spiritual community membership were protective against African American youth suicidality. Greening and Stoppelbein defined orthodoxy, a correlate of intrinsic religiosity, as the commitment to core religious beliefs (e.g., Christian doctrines such as the belief that suicide is not an acceptable solution to problems) [23]. Orthodoxy was found to be protective against suicide risk for African American adolescents [23]. Intrinsic religiosity, defined as a religious-based framework for meaningfulness in one's life, had a direct, inverse effect on depressive symptomology, which was found to be protective against suicidal ideation [58]. The coping strategy of collaborative religious problem solving (i.e., the belief that God and the individual work together, as partners, to solve problems) was identified as protective factor against suicidal ideation [40]. Religious awareness was only protective against female African American adolescents' suicidal ideation and behaviors when reasons for living mediated that relationship [60]. Lastly, perceived spiritual community membership was protective against suicidal ideation, though not attempts, for urban African American youth [16]. In line with Durkheim's beliefs that religious involvement provided a means for social integration and thus protection against suicidality, this review revealed that religiosity-based factors, such as belonging to a spiritual community, and intrinsic religious-based factors such as following Christian doctrines and having a collaborative relationship with God provided protection against suicidality for African American youth [14]. Religiosity-based factors were protective for both females and males; however, religious awareness, when accompanied by reasons for living, was only protective for female suicidal ideation.

Although several religious-based factors were identified as protective, particularly those of a more intrinsic nature, there were a number of religious-based factors that were not protective against suicidality. Only one study assessed, but did not find support for, religious-based protective factors among African American youth from low-income, urban backgrounds [16]. More specifically, church membership, religious importance, and prayer frequency did not protect urban African American adolescents from suicidality. Among African American adolescents from a variety of socioeconomic backgrounds, church attendance, religious importance, religiosity, self-directing religious problemsolving (i.e., actively tried to solve one's own problems without God's help), deferring religious problem-solving (i.e., let God provide solutions to problems, rather than coming up with solutions for oneself), and extrinsic religiosity (i.e., social and personal benefits of religious practice/behavior) were not found to be protective against suicidality $[2,4,4048,58]$. Overall, for African American adolescents, religious-based factors of a more extrinsic nature were not identified as protective against suicidality, and no religious-based factors were protective for urban youth.

\section{Relational/Social Factors}

Social integration theory purports that individuals who are socially integrated into their community have protection against adverse outcomes, such as suicide, through the support provided by a cohesive community bound together by collective societal norms [14]. Thus, protection may be gained from the social support and guidance acquired from the community and the relationships that help to promote social integration. The present study identified 12 articles that reported on relational and social factors as possible protective factors for African American adolescent suicidality $[2,15,28,34,35,40,41,46-48,50,58]$. Dense school social networks, school connectedness/attachment, school climate, transitive relationships, having popular friends, peer connectedness and support, perceived social support, formal network activation, and community connectedness were relational/ social factors identified as protective against African American adolescent suicidality. Bearman and Moody identified dense (i.e., tightly-knit) school social networks that linked adolescents together as protective against suicidal ideation for females and suicide attempt for males [2]. School connectedness/attachment, defined as students feeling happy at school, feeling that they were a part of the school, and feeling that they were close to people at school, was found to be protective against suicide attempt for females, males with a history of suicide attempts, and both males and females in three separate studies [28,34,50]. Among African American adolescent males with a history of previous attempts and poor peer relations, school connectedness moderated the relationship between parent/family connectedness and suicide attempt to create a stronger protective effect [34]. School climate (i.e., school environment, teacher attention/compassion) was identified as a protective factor for suicidal ideation among males and suicidal attempt among both males and females [48]. Transitive relationships (i.e., closed, dense friendship networks where an adolescent's friends are friends with each other) provided protection against suicidal ideation for female African American adolescents [2]. Having popular friends was protective against suicide attempt for females [28]. Feeling connected to one's peers was protective for males with a history of suicide attempts whereas feeling supported by one's peers was protective against suicide ideation and attempts for adolescent of varying socioeconomic backgrounds including protection against suicide attempt for low-income, urban youth $[34,41,15]$. Perceived general social support (e.g., support from family, platonic friends, boyfriends/ girlfriends) was protective against suicidal ideation for adolescents of various socioeconomic backgrounds [35,58]. General social support was also protective against suicidal ideation for female low-income, urban African American adolescents and suicidal ideation and attempts for males. O'Donnell and colleagues also found that accessing a formal network (i.e., school, religious, health care, or mental health networks) for help with problems was protective for urban adolescent suicide attempt [47]. Lastly, perceived community connectedness was protective against suicidality for adolescents at higher levels of depression [41]. Overall, feeling supported by others, having close-knit friendship groups, and feeling connected to social groups (i.e., peers, school, community) protected urban and other socioeconomic status African American youth from suicidality. Having popular friends and transitive relationships were protective for females, whereas 
peer connectedness was protective for males. Accessing formal networks for additional support was found to be protective for urban African American youth suicidality.

Several relational/social factors were identified as protective against African American adolescent suicidality; however, mixed and non-significant results were also identified for some relational/social factors. Among youth of various socioeconomic backgrounds and low-income, urban African American youth there were mixed findings for peer support as a protective factor for suicidality $[41,40,15,46]$. School attachment, identified as protective for African American adolescents of various socioeconomic backgrounds was not a significant protective factor for urban African American youth suicidality [28,34,50,46]. Similarly, school bonding (i.e., frequency an adolescent talked to a teacher about a problem) was not protective for urban adolescents' suicidality [16]. Other factors that were not protective for African American adolescents of various socioeconomic backgrounds were network centrality (i.e., direct links to others in one's friendship network; only assessed for females), perceived supportive college community, having friends, popularity, and involvement in extracurricular activities $[28,35,48]$. For urban African American youth in particular, school settings (e.g., attachment to and teacher support) were not protective against suicidality, whereas they did provide protection for African American youth of various socioeconomic backgrounds. Overall, there were several relational/social factors that were protective against African American adolescent suicidality; however, a number of mixed findings suggest that there may be characteristics unique to the different samples that may account for the differing results.

\section{Personal Factors}

Personal factors are comprised of a large variety of individual characteristics and traits that may impact various aspects of a person's life, such as their relationships, social integration, and suicidality. Fourteen studies reported on the effectiveness of personal factors as being protective against suicidality $[2,3,12,15,16,23,24,28,40,46,48,59-61]$. Personal factors identified as protective against African American adolescent suicidality were age, self-esteem, emotional well-being, academic achievement/grade point average, hope, ascribing to an adaptive attributional style, avoidance-oriented coping, negative attitude toward suicide acceptability, reasons for living, purpose in life, and life satisfaction. Older age was protective against suicidal ideation for both male and female adolescents of various socioeconomic backgrounds [48]. Younger age, however, was protective against suicide attempt for urban adolescents [15]. Higher self-esteem was identified as protective against suicidal ideation for males and females, and suicide attempt for females [2]. Self-esteem was also protective against suicidal ideation and attempt for male and female urban African American youth [16]. Emotional well-being protected female adolescents from suicide attempt [3]. Academic achievement/grade point average was protective against suicide attempt for African American males [3]. Davidson and colleagues identified a sense of hope as a protective factor for male and female suicidal ideation [12]. Within the realm of coping strategies, ascribing to an adaptive attributional style (i.e., external, unsta- ble, specific attributions for negative events; internal, stable, and global attributions for positive events) protected youth against suicide risk [23]. Avoidance-oriented coping represented another coping strategy that was protective against suicidal ideation and attempts via a positive association with reasons for living $[59,61]$. Having a negative attitude toward suicide acceptability was protective for female suicidal ideation [40]. Having reasons for living (i.e., adaptive reasons that support not committing suicide) was protective against female suicidal thoughts and behaviors suicidal ideation and attempt adolescents from various socioeconomic backgrounds and suicidal ideation among urban African American youth [59-61,24]. Wang and colleagues found that purpose in life protected a sample of predominantly European and African American adolescents (ethnic differences were not indicated in the results) from suicidal ideation and attempts via an inverse relationship with depression [59]. Lastly, life satisfaction protected male African American adolescents from suicidal ideation and attempts [60]. Overall, a wide range of personal factors were protective, including fixed traits (e.g., age), behaviors (e.g., academic achievement), and mental health-related factors (e.g., well-being, self-esteem). Having an adaptive attributional style and being able to avoid, or shut out problems, were protective coping strategies for African American youth suicidality. Gender differences were found, such that well-being and reasons for living were protective for female African American adolescents only, and academic achievement and life satisfaction were protective for males only.

While a variety of personal factors were identified as protective for African American adolescent suicidality, a range of personal factors were also identified as not being protective against suicidality. Although three studies identified reasons for living as protective against suicidality, Marion and Range found that reasons for living were not protective for female suicidal ideation (only females were assessed) [40]. Academic achievement/ GPA was protective against suicide attempt for males, whereas school engagement (i.e., paying attention, getting homework completed) was not protective against suicide attempt [28]. Various coping styles were also non-significant protective factors for suicidality, including task-oriented coping (i.e., active attempts at problem-solving) and emotion-focused coping (i.e., reacting emotionally to stressful situations) [61]. "John Henry" style coping (i.e., actively managing psychosocial stressors through positive orientation toward the future and hard work) was not protective for urban African American youth suicidal ideation [46]. O'Donnell and colleagues also did not find evidence to support ethnic identity formation as a protective factor for suicidal ideation [46]. There were mixed results for academic-related factors, and the more active coping strategies (e.g., problem-focused, "John Henry" style for urban youth) were not effective at protecting African American youth from suicidality. Overall, African American youth gained more protection from suicidality through avoiding problems rather than dealing with problems and contextual circumstances directly.

\section{Socioecological Factors}

There are numerous socioecological factors that may 
impact one's ability to socially integrate into society, such as employment, income, housing, and collective beliefs and norms, which, in turn, may provide protection against suicidality [14]. The present study identified seven studies that reported on the protective effects of socioecological factors. Increased socioeconomic status, decreased residential mobility, residing in southern or western regions, and collective efficacy were found to be protective against African American adolescent suicidality. Burr and colleagues identified an inverse relationship between socioeconomic status (i.e., income and occupation) and suicide risk, thus, increased socioeconomic status was found to be protective against suicide risk [4]. Three studies identified decreased residential mobility as a protective factor against suicidality. Living in one's current residence for more than two years was protective against suicide attempt for females [28]. Longer durations of time spent living in one residence was protective against suicide attempt for male and female adolescents [39]. Having lived in the same community for more than five years was found to be a marginally significant protective factor for urban African American adolescents [46]. Joe and colleagues identified southern and western U.S. regions of residence as protective against suicide attempt for African American adolescents (as compared to adolescents living in northeastern regions) [31]. Lastly, collective efficacy, defined as community members' mutual trust and willingness to promote the common good and, consequently, facilitate informal social control, moderated the relationship between family support and suicidal ideation, such that collective efficacy strengthened the protective effect of family support [39]. Overall, positive socioecological factors, such as increased socioeconomic status, not having to move around, living in certain regions of the United States, and collective efficacy were protective against suicidality for both female and male African American adolescents.

Two studies identified factors that were not protective against suicidality. Harris and Molock found that communalism (having strong communal values) actually increased suicidal ideation among African American adolescents [26]. Farrell and colleagues found that neither living in one's residence for more than one year, nor contextual safety (perceived safety of one's social environment) were protective factors for urban African American youth suicide attempt [15]. Studies from this review provided mixed results for support of socioecological factors as protective against African American adolescent suicidality. Durkheim's social integration theory describes shared, communal values as being a component of social integration that helps to strengthen societal bonds [14]. Communal values, however, were not found to be protective of suicidality among African American adolescents; rather, strong communal values promoted suicidal ideation. Socioecological factors (i.e., residential stability and perception of a safe environment) were not found to be protective for urban African American youth.

\section{Discussion}

\section{Suicidality Protective Factors}

This review identified a total of 26 studies that met inclusion criteria, in an attempt to identify factors that attenuate suicidality among African American adolescents. The present study found a variety of factors protective for African American adolescent suicidality. Further, protective factors for African American adolescent suicidality were able to be organized into a categorical framework that provided support for Durkheim's social integration theory [14]. Protective factors were categorized as either familial (e.g., parent-family connectedness, family support), religiosity-based (e.g., intrinsic religiosity, collaborative religious problem solving), relational/social (e.g., peer connectedness, perceived social support), personal (e.g., emotional wellbeing, reasons for living), and socioecological (e.g., increased socioeconomic status, decreased residential mobility). Additionally, the present review revealed factors that attenuate suicidality among low-income, urban, African American adolescents and the presence of gender differences among protective factors for suicidality.

Overall, identified protective factors for suicidality coincided with factors that may promote social integration, through which one may obtain support, guidance, and protection from suicide. Durkheim noted that familial, relational/social, and religious ties were the mechanisms through which one achieved social integration [14]. Personal factors may contribute to the initiation and preservation of some of the afore-mentioned relational bonds, which may impact the feasibility of social integration. Socioecological factors play a role in social integration theory as well, given that they may present challenges and barriers, such as an unemployed or underemployed individual needing to move away from one's family and community in order to find work, possibly deterring one's integration into society.

The most strongly supported factors protective against African American adolescent suicidality were familial, relational/ social, and personal factors, followed by the lesser-studied religiosity based and socioecological factors. Feeling connected to supportive and accessible family members, being a part of a cohesive family, and having high quality relationships with parents represent the types of familial factors that protect against suicidality for African American youth from a variety of socioeconomic backgrounds.

African American Christian churches have long been suggested to provide protection against suicidality for African Americans [18,44]. Overall, religiosity-based factors of an intrinsic nature (based on the adoption of a religious-based framework to provide meaning in one's life), rather than extrinsic religiosity (i.e., emphasis on the benefits of religious practices/behavior) were protective against African American adolescent suicidality [58]. Religious coping that involved a collaborative problemsolving approach, in which the individual works with God to solve problems in one's life, also was protective against suicidality. Perhaps not surprisingly, more extreme types of coping, in which the individual either loses all agency in the problem-solving process (i.e., deferring problem-solving), or does not involve God at all in the process (i.e., self-directive problem-solving) were not protective against suicidality for African American youth [58]. Although church membership is a route to social integration, according to Durkheim, it received mixed results as a protective factor [14]. However, church membership has been found to be protective against suicidality for African American men [4]. It may be that 
church membership becomes more desirable with age; although, more research is necessary to investigate this relationship.

Several significant protective relational/social factors emerged from this review. Tightly-knit friendship networks, supportive social networks, school attachment, and community connectedness represent some of the factors protective against suicidality for African American youth suicidality from a variety of socioeconomic backgrounds. Having these social bonds may be indicative of social integration, which Durkheim purported is protective against suicide [14]. Study results support Durkheim's theory of social integration. Peer support had mixed results, which may suggest that peer networks may not be the best and most stable sources of support for African American youth suicidality. Further investigation is warranted.

Numerous personal factors or characteristics unique to the adolescents, such as self-esteem, emotional well-being, academic achievement, etc., were protective against suicidality. Having some of these personal competencies may be associated with better mental health and may contribute to more positive outlooks. It makes sense that someone who has high self-esteem, a high grade point average, and who has many reasons for living may be less at risk for suicidality than individuals who do not have those personal factors. Contextual factors of different environments may make it more or less likely for youth to have positive personal competencies.

Socioecological factors, including higher socioeconomic status, decreased residential mobility, residing in southern or western regions, and collective efficacy were protective against youth suicidality. These factors are directly associated with one's environment. Durkheim noted that socioeconomic status may impact one's ability to socially integrate into society, such that lower socioeconomic status may present more challenges to social integration [14]. Residential mobility may be a consequence of one's socioeconomic status and may be disruptive to the social relationships that bring about social integration [28]. Thus, increased socioeconomic status and decreased residential mobility may facilitate social integration and provide protection against suicidality. Collective efficacy (i.e., community members' mutual trust and willingness to act on behalf of the common good), a goal and byproduct of Durkheim's notion of social integration, may help to promote a sense of cohesion and belongingness that provides some protection against suicide attempt [39]. Interestingly, communalism (i.e., having strong communal values) was found to increase suicidality. Promoting the common good was a pervasive component of collective efficacy; however, the content underlying the communal values was not mentioned. Perhaps the content of the communal values may have been more adversely impactful than the shared nature of the values was beneficial.

The present study identified multiple protective factors for African American adolescent suicidality. Protective factors were categorized into several categories (i.e., familial, religiositybased, relational/social, personal, and socioecological) that, overall, provide support for Durkheim's social integration theory of suicide protection. There is a dearth of current literature on the topic of African American youth suicide. More research needs to be completed in order to understand current contextual and pro- tective factors for these youth. Additionally, there is a need to examine ways in which to promote protective factors for African American adolescents.

\section{Low-Income, Urban African American Youth}

Differences in protective factors for urban African American adolescents, compared to African American adolescents of various socioeconomic backgrounds, may suggest that this particularly at-risk population have different or additional vulnerabilities that require further investigation in order to identify effective protective factors for suicidality. Given that only five studies were identified by this review process as investigating protective factors for suicidality among urban African American adolescents and only three of those studies were completed within this most recent decade it is clear that there is a great need for further research addressing suicidality within this population $[15,16,24,46,47]$.

Family closeness and family network availability were the only familial factors identified as protective for urban African American youth suicidality $[46,47]$. Parental involvement, supervision, support, warmth, and family alliance were not protective against urban youth suicidality $[15,16,24]$. Low-income African American youth living in under-resourced areas are at greater risk of family dysfunction and breakdown suggesting that positive familial factors such as parental involvement, support, warmth, etc. may be less readily available when families are unstable and faced with a multitude of contextual stressors [10,36]. Financial strain may require that some parents work more and stay home less, potentially prohibiting them from being more involved with their children or supervising them.

Only one study assessed the protective impact of religiosity-based factors [16]. Perceived spiritual community membership was the only factor identified as protective against suicide for urban African American adolescents. Religious importance and prayer frequency were not found to be protective. Spiritual community membership may provide social support and social integration for urban African American youth; however, given that only one study assessed religiosity-based protective factors for this population, more research is needed to further explore this relationship.

Low-income African American youth, like African American youth from different socioeconomic backgrounds, reported that general social support was protective against suicide attempt. However, school bonding and attachment were not found to be protective among low-income youth. Under-resourced schools in low-income neighborhoods may not have been able to provide the same positive, protective environment as schools in higher-income areas.

Personal factors, such as self-esteem and reasons for living may be impacted by contextual factors of one's environment. Youth living in under-resourced, low-income areas are at increased risk of having fewer positive personal competencies than youth living in higher-income areas. Self-esteem and reasons for living were protective against suicidality for low-income African American adolescents; however, many of the personal factors identified as protective for youth from various socioeco- 
nomic backgrounds were not assessed among low-income adolescent populations. Future research may be able to identify additional personal factors that may be protective for low-income African American adolescents.

Residential mobility and contextual safety (i.e., perceived safety of one's environment) were the only socioecological factors assessed for low-income African American youth [15]. Results provided mixed support for decreased residential mobility as protective against suicidality, while contextual safety was not found to be protective for low-income African American suicidality. Clearly, more research is needed to understand whether socioecological factors may provide some protection against lowincome African American suicidality.

Overall, there is a large dearth of information on protective factors for low-income African American adolescent suicidality. The five identified studies provide some information about possible protective factors, but more research must be completed to have a more informed understanding of factors that mitigate suicidality for this vulnerable population. Further, given the lack of resources available to these youth, future research may wish to focus effort on identifying what resources are needed to help promote suicidality protective factors.

\section{Gender Differences}

Gender differences were found for several of the factors that protected African American youth from suicidality. A summary of gender differences may be found in (Tables 1,2). Overall, familial factors were protective for both male and female African American adolescents. Dense school social networks and transitive friendships were protective only against female suicidal ideation, while dense school social networks provided protection against male suicide attempt. Peer and school connectedness was protective only for males with a history of suicide attempts. In general, females were more protected by relational/social factors than were males. Gender differences were not indicated for religiosity-based protective factors. Personal factors related to psychological well-being were more protective against female suicide attempt, while academic-oriented factors were more protective for males. Female African American adolescents were more likely to be adversely impacted by residential mobility, due to the disruption of social networks and relationships [28].

\section{Limitations}

The present review of the research literature on protective factors for African American youth suicidality yielded a modest 26 accessible studies. Due to the relatively small number of available studies, we broadened our inclusion criteria, in order to review the largest number of studies; however, the broadened inclusive criteria may have contributed to decreased specificity of outcomes. For example, there was no time-frame in which articles needed to be published. As a result, we obtained 12 studies that were more than 10 years old, 12 studies that utilized data from 20 or more years ago, and eight studies that utilized data from 10 or more years ago [2,3,4,23,26,35,40,46$48,50,17,28,34,35,39,42,15,16,24,31]$. Data utilized by older studies may yield potentially less relevant findings than more re- cent studies that may have been able to take into consideration more current and potentially influential contextual factors. The age range criteria (i.e., 10-24 years old) for study participants also were very broad. Factors protective for suicidality among 10-15-year-olds may not impact 18-24-year-olds in a similar manner or through a similar route. Adolescents of such a wide range of ages inevitably experienced different developmental stages, which may have impacted results. Many of the studies reviewed involved adolescents from a wide age range (e.g., 11-21 years, as in the Add Health study), but did not necessarily report on age differences; thus, it is unclear from these samples whether younger versus older adolescents were impacted differently by protective factors.

Other study limitations involve multiple articles reporting on datasets from the same study. Six studies utilized data from the longitudinal, multi-wave National Longitudinal Study of Adolescent Health (i.e., Add Health study) [2,3,17,28,34,50]. The study was initiated in 1994 and assessed health status, risk behaviors, and social contexts of adolescents from 132 middle and high schools, their parents, friends, schools, and neighborhoods [28]. None of the six studies utilized exactly the same subsamples of Add Health U.S. representative adolescents; although, it was not always clearly indicated from which year/wave data was being used. Similarly, two of the articles that assessed protective factors for urban African American youth utilized data from the same dataset $[46,47]$. In the case of the studies by O'Donnell and colleagues, it meant that only four different samples of urban African American youth were assessed for factors pertaining to suicidality $[46,47]$. This highlights the need for more suicidality protective factor research among urban African American youth. Additionally, although it is common for the same dataset to be used in more than one study, it may limit the generalizability of findings.

Different assessment measures of key constructs represent additional study limitations. Although many of the reviewed studies assessed the same constructs, in some cases, they employed different measures to assess these constructs. For example, studies utilizing the Add Health data assessed both suicidal ideation and suicide attempts with single items. Suicidal ideation and number of suicide attempts within the past year were reported [28]. Joe and colleagues assessed suicidality through the World Health Organization Composite International Diagnostic Interview (CIDI) [33]. The CIDI assessed suicidal ideation, plan, and attempt within the past year and lifetime. Fitzpatrick and colleagues measured only suicide attempt by a single, dichotomous-response item: "Have you ever tried to kill yourself?" Still other studies utilized different composite measures to assess suicidality [16]. Given that the assessment measures often define the construct, utilizing a variety of measures/items may lead to a variety of operational definitions for various constructs. For example, suicidal thoughts and behaviors may refer to ideation and attempts for some studies, or suicidal ideation, plans, and attempts for others. 


\section{Conclusion}

This review identified 26 studies that reported on protective factors for African American adolescents. Twenty of the reviewed studies involved African American youth from a variety of socioeconomic backgrounds, whereas only five of the reviewed studies assessed protective factors for urban, low-income African American youth. Gender differences also were assessed. Several protective factors were identified that may be categorized as either familial, religiosity-based, relational/social, personal, or socioecological. Familial factors, such as feeling connected to a cohesive family, and having supportive, high-quality relationships with family members (e.g., parents) were protective against suicidality for female and male African American adolescents of various socioeconomic backgrounds. Familial factors were less protective for urban, low-income African American youth. Overall, having a sense of belonging to a spiritual community, along with intrinsic religious-based factors (e.g., adhering to Christian doctrines, having a collaborative relationship with God) were protective for female and male African American adolescents from various socioeconomic backgrounds. Only one study assessed religiosity-based factors among urban African American youth and did not find evidence that these factors were supportive for this population. Relational/social factors, such as feeling connected to and supported by others and having close-knit friendship groups, were protective for female and male African American adolescent suicidality. Having transitive relationships and popular friends were protective factors for female African American adolescents. Accessing a formal network for support was uniquely protective for urban African American adolescent suicidality. Although school-based factors were protective for African American youth of various socioeconomic backgrounds, they were not supportive for urban African American youth. A variety of personal factors were protective against African American youth suicidality, such as age (older for general African American adolescents, younger for urban African American adolescents), academic achievement and life-satisfaction (protective for males), well-being and reasons for living (protective for females), an adaptive attribution style (protective for females and males), hope (protective for females and males), and self-esteem (protective for urban African American youth). Additionally, avoidant coping was protective against African American youth suicidality, whereas more active and problem-solving coping was not. Socioecological factors, such as increased socioeconomic status, living in southern or western regions of the U.S., and collective efficacy, were protective against African American adolescent suicidality. Increased residential stability was protective for youth of various socioeconomic backgrounds, but not for urban African American youth. Having strong communal values was not protective for urban African American youth.

The present study identified numerous protective factors; however, there is only a modest amount of literature available that assessed protective factors for African American youth suicidality. Further, there is a dearth of literature involving current data. More research is needed, particularly among lowincome, urban African American adolescents, to identify factors that protect against suicidality, in order to inform future preven- tion/intervention programs, policies, and treatment for these vulnerable youth.

\section{Acknowledgements}

This research was supported by a grant from the National Institute of Child Health and Human Development (grant number HD072293).

\section{References}

1. Balis T, Postolache TT. Ethnic Differences in Adolescent Suicide in the United States. Int J Child Health Hum Dev. 2008;1(3):281-296.

2. Bearman PS, Moody J. Suicide and friendships among American adolescents. Am J Public Health. 2004;94(1):89-95.

3. Borowsky IW, Ireland M, Resnick MD. Adolescent suicide attempts: Risks and protectors. Pediatrics. 2001;107(3):485-493.

4. Burr JA, Hartman JT, Matteson DW. Black suicide in U.S. metropolitan areas: An examination of the racial inequality and social integrationregulation hypotheses. Social Forces. 1999;77(3):1049-1081. doi: $10.2307 / 3005971$

5. Centers for Disease Control and Prevention. Leading causes of death reports, national and regional, 1999-2012. WISQARS. 2012a. Retrieved from http://webappa.cdc.gov/sasweb/ncipc/leadcaus10_us.html

6. Centers for Disease Control and Prevention. Suicide prevention: Youth suicide. Injury Center: Violence Prevention. 2012b.

7. Centers for Disease Control and Prevention. Youth Risk Behavior Surveillance System (YRBSS). Adolescent and School Health. 2013. Retrieved from http://www.cdc.gov/healthyyouth/yrbs/index.html

8. Chu JP, Goldblum P, Floyd R, Bongar B. The cultural theory and model of suicide. Applied and Preventive Psychology. 2010;14(1),25-40. doi: 10.1016/j.appsy.2011.11.001

9. Colucci E, Martin G. Ethnocultural aspects of suicide in young people: a systematic literature review part 2: Risk factors, precipitating agents, and attitudes toward suicide. Suicide Life Threat Behav. 2007;37(2):222-237. doi: 10.1521/suli.2007.37.2.222

10. Compton MT, Thompson NJ, Kaslow NJ. Social environment factors associated with suicide attempt among low-income African Americans: the protective role of family relationships and social support. Soc Psychiatry Psychiatr Epidemiol. 2005;40(3):175-185. doi: 10.1007/ s00127-005-0865-6

11. Crosby A, Molock SD. Suicidal Behaviors in the African American Community. J Black Psychol. 2006;32(3):1-9. doi: $10.1177 / 0095798406290552$

12. Davidson CL, Wingate LR, Slish ML, Rasmussen KA. The Great Black Hope: Hope and its relation to suicide risk among African Americans. Suicide Life Threat Behav. 2010;40(2):170-180. doi: 10.1521/ suli.2010.40.2.170

13. Dupéré V, Leventhal T, Lacourse E. Neighborhood poverty and suicidal thoughts and attempts in late adolescence. Psychol Med. 2009;39(8):1295-1306. doi: 10.1017/S003329170800456X

14. Durkheim E. Suicide (J. A. Spaulding \& G. Simpson, Trans.). New York: Free Press (Original work published 1897). 1951. 
15. Farrell CT, Bolland JM, Cockerham WC. The role of social support and social context on the incidence of attempted suicide among adolescents living in extremely impoverished communities. J Adolesc Health. 2015;56(1):59-65. doi: 10.1016/j.jadohealth.2014.08.015

16. Fitzpatrick KM, Piko BF, Miller E. Suicide ideation and attempts among low-income African American adolescents. Suicide Life Threat Behav. 2008;38(5):552-563. doi: 10.1521/suli.2008.38.5.552

17. Gangwisch JE, Babiss LA, Malaspina D, Turner JB, Zammit GK, Posner K. Earlier parental set bedtimes as a protective factor against depression and suicidal ideation. Sleep. 2010;33(1):97-106.

18. Gibbs JT. African-American suicide: a cultural paradox. Suicide Life Threat Behav. 1997;27(1):68-79.

19. Goldston DB. Conceptual issues in understanding the relationship between suicidal behavior and substance use during adolescence. Drug Alcohol Depend. 2004;76 Suppl:S79-91. doi: 10.1016/j.drugalcdep.2004.08.009

20. Goldston DB, Daniel SS, Erkanli A, Reboussin BA, Mayfield A, Frazier $\mathrm{PH}$, et al. Psychiatric diagnoses as contemporaneous risk factors for suicide attempts among adolescents and young adults: developmental changes. J Consult Clin Psychol. 2009;77(2):281-90. doi: 10.1037/ a0014732

21. Goldston DB, Molock SD, Whitbeck LB, Murakami JL, Zayas LH, Hall GC. Cultural considerations in adolescent suicide prevention and psychosocial treatment. Am Psychol. 2008;63(1):14-31. doi: 10.1037/0003066X.63.1.14

22. Gould MS, Greenberg T, Velting DM, Shaffer D. Youth suicide risk and preventive interventions: a review of the past 10 years. J Am Acad Child Adolesc Psychiatry. 2003;42(4):386-405. doi: 10.1097/01. CHI.0000046821.95464.CF

23. Greening L, Stoppelbein L. Religiosity, attributional style, and social support as psychosocial buffers for African American and white adolescents' perceived risk for suicide. Suicide Life Threat Behav. 2002;32(4):404-417.

24.Gutierrez PM, Muehlenkamp JJ, Konick LC, Osman A. What role does race play in adolescent suicidal ideation? Archives Arch Suicide Res. 2005;9(2):177-192. doi: 10.1080/13811110590904025

25. Harris EC, Barraclough B. Suicide as an outcome for mental disorders A meta-analysis. The Br J Psychiatry. 1997;170:205-228.

26. Harris TL1, Molock SD. Cultural orientation, family cohesion, and family support in suicide ideation and depression among African American college students. Suicide Life Threat Behav. 2000;30(4):341-353.

27. Hawton K, Saunders KE, O'Connor RC. Self-harm and suicide in adolescents. Lancet. 2012;379(9834):2373-2382. doi: 10.1016/S01406736(12)60322-5

28. Haynie DL, South SJ, Bose S. Adolescent mobility and suicide attempts. Sociological Quarterly. 2006;47:693-721.

29. Huth-Bocks AC, Kerr DC, Ivey AZ, Kramer AC, King CA. Assessment of psychiatrically hospitalized suicidal adolescents: self-report instruments as predictors of suicidal thoughts and behavior. J Am Acad Child Adolesc Psychiatry. 2007;46(3):387-395. doi: 10.1097/

\section{chi.0b013e31802b9535}

30. Joe S. Implications of National Suicide Trends for Social Work Practice with Black Youth. Child Adolesc Social Work J. 2006;23(4):458-471. doi: 10.1007/s10560-006-0064-7

31. Joe S, Baser RS, Neighbors HW, Caldwell CH, Jackson JS. 12-month and lifetime prevalence of suicide attempts among black adolescents in the National Survey of American Life. J Am Acad Child Adolesc Psychiatry. 2009;48(3):271-282. doi: 10.1097/CHI.0b013e318195bccf

32. Joe S, Kaplan MS. Suicide among African American men. Suicide Life Threat Behav. 2001;31:106-121.

33. Kessler RC, Wittchen HU, Abelson JM, Mcgonagle K, Schwarz N, Kendler KS, et al. Methodological studies of the Composite International Diagnostic Interview (CIDI) in the US national comorbidity survey (NCS). International Journal of Methods in Psychiatric Research. 1998;7(1):33-55. doi: 10.1002/mpr.33

34. Kidd S, Henrich CC, Brookmeyer KA, Davidson L, King RA, Shahar G. The social context of adolescent suicide attempts: interactive effects of parent, peer, and school social relations. Suicide Life Threat Behav. 2006 Aug;36(4):386-395. doi: 10.1521/suli.2006.36.4.386

35. Kimbrough RM, Molock SD, Walton K. Perception of social support, acculturation, depression, and suicidal ideation among African American college students at predominantly Black and predominantly White universities. Journal of Negro Education. 1996;65(3):295-307. doi: $10.2307 / 2967346$

36. Kubrin CE, Wadsworth T, DiPietro S. Deindustrialization, disadvantage and suicide among young Black males. Social Forces. 2006;84(3)15591579.

37. Langhinrichsen-Rohling J, Friend J, Powell A. Adolescent suicide, gender, and culture: A rate and risk factor analysis. Aggression and Violent Behavior. 2009;14(5):402-414. doi: 10.1016/j.avb.2009.06.010

38. Lincoln KD, Taylor RJ, Chatters LM, Joe S. Suicide, negative interaction and emotional support among black Americans. Soc Psychiatry Psychiatr Epidemiol. 2012;47(12):1947-1958. doi: 10.1007/s00127012-0512-y

39. Maimon D, Browning CR, Brooks-Gunn J. Collective efficacy, family attachment, and urban adolescent suicide attempts. J Health Soc Behav. 2010;51(3):307-24. doi: 10.1177/0022146510377878

40. Marion MS, Range LM. African American college women's suicide buffers. Suicide Life Threat Behav. 2003;33(1):33-43.

41. Matlin SL, Molock SD, Tebes JK. Suicidality and depression among African American adolescents: the role of family and peer support and community connectedness. Am J Orthopsychiatry. 2011;81(1):108117. doi: 10.1111/j.1939-0025.2010.01078.x

42. McKeown RE, Garrison CZ, Cuffe SP, Waller JL, Jackson KL, Addy CL. Incidence and predictors of suicidal behaviors in a longitudinal sample of young adolescents. J Am Acad Child Adolesc Psychiatry. 1998 Jun;37(6):612-619. doi: 10.1097/00004583-199806000-00011

43. Merikangas KR, He JP, Burstein M, Swendsen J, Avenevoli S, Case B. Service utilization for lifetime mental disorders in U.S. adolescents: results of the National Comorbidity Survey-Adolescent Supplement 
(NCS-A). J Am Acad Child Adolesc Psychiatry. 2011;50(1):32-45. doi: 10.1016/j.jaac.2010.10.006

44. Molock SD, Matlin S, Barksdale C, Puri R, Lyles J. Developing suicide prevention programs for African American youth in African American churches. Suicide Life Threat Behav. 2008;38(3):323-333. doi: 10.1521/suli.2008.38.3.323

45. O'Carroll PW, Berman AL, Maris RW, Moscicki EK, Tanney BL, Silverman MM. Beyond the Tower of Babel: a nomenclature for suicidology. Suicide Life Threat Behav. 1996;26(3):237-252.

46. O'Donnell L, O'Donnell C, Wardlaw DM, Stueve A. Risk and resiliency factors influencing suicidality among urban African American and Latino youth. Am J Community Psychol. 2004;33(1-2):37-49.

47. O’Donnell L, Stueve A, Wardlaw D, O’Donnell C Adolescent suicidality and adult support: the reach for health study of urban youth. Am J Health Behav. 2003;27(6):633-644.

48. Perkins DF, Hartless G. An ecological risk-factor examination of suicide ideation and behavior of adolescents. Journal of Adolescent Research. 2002;17(1),3-26. doi: 10.1177/0743558402171001

49. Posner K, Brown GK, Stanley B, Brent DA, Yershova KV, Oquendo MA. The Columbia-Suicide Severity Rating Scale: initial validity and internal consistency findings from three multisite studies with adolescents and adults. Am J Psychiatry. 2011;168(12):1266-1277. doi: 10.1176/ appi.ajp.2011.10111704

50. Resnick MD, Bearman PS, Blum RW, Bauman KE, Harris KM, Jones J. Protecting adolescents from harm. Findings from the National Longitudinal Study on Adolescent Health. JAMA. 1997;278(10):823-832.

51.Santiago CD, Kaltman S, Miranda J. Poverty and mental health: how do low-income adults and children fare in psychotherapy? J Clin Psychol. 2013;69(2):115-26. doi: 10.1002/jclp.21951

52. Shaffer D, Gould M, Hicks RC. Worsening suicide rate in black teenagers. Am J Psychiatry. 1994;151(12):1810-1812. doi: 10.1176/ ajp.151.12.1810

53. Spann M, Molock SD, Barksdale C, Matlin S, Puri R. Suicide and African American teenagers: risk factors and coping mechanisms. Suicide Life Threat Behav. 2006;36(5):553-568. doi: 10.1521/suli.2006.36.5.553

54.Stack S. Suicide: a 15-year review of the sociological literature. Part I: cultural and economic factors. Suicide Life Threat Behav. 2000;30(2):145-162.
55.Summerville MB, Kaslow NJ, Abbate MF, Cronan S. Psychopathology, family functioning, and cognitive style in urban adolescents with suicide attempts. J Abnorm Child Psychol. 1994;22(2):221-235.

56. United States Census Bureau. Annual Social and Economic Supplement. Current Population Survey. 2012

57. Utsey SO, Hook JN, Stanard P. A re-examination of cultural factors that mitigate risk and promote resilience in relation to African American suicide: a review of the literature and recommendations for future research. Death Stud. 2007;31(5):399-416. doi: 10.1080/07481180701244553

58. Walker RL, Bishop S. Examining a model of the relation between religiosity and suicidal ideation in a sample of African America and White college students. Suicide Life Threat Behav. 2005 Dec;35(6):630-639.

59. MC, Richard Lightsey O, Pietruszka T, Uruk AC, Wells AG. Purpose in life and reasons for living as mediators of the relationship between stress, coping, and suicidal behavior. The Journal of Positive Psychology. 2007;2(3):195-204. doi: 10.1080/17439760701228920

60. Wang MC, Lightsey OR Jr, Tran KK, Bonaparte TS. Examining suicide protective factors among black college students. Death Stud. 2013;37(3):228-247. doi: 10.1080/07481187.2011.623215

61. Wang MC, Nyutu PN, Tran KK. Coping, reasons for living, and suicide in Black college students. Journal of Counseling \& Development. 2012;90(4):459-466. doi: 10.1002/j.1556-6676.2012.00057

62. Willis LA, Coombs DW, Cockerham WC, Frison SL. Ready to die: a postmodern interpretation of the increase of African-American adolescent male suicide. Soc Sci Med. 2002;55(6):907-920.

63. Willis LA, Coombs DW, Drentea P, Cockerham WC. Uncovering the mystery: factors of African American suicide. Suicide Life Threat Behav. 2003;33(4):412-429.

64. Wingate LR, Bobadilla L, Burns AB, Cukrowicz KC, Hernandez A, Ketterman RL, et al. Suicidality in African American men: the roles of southern residence, religiosity, and social support. Suicide Life Threat Behav. 2005;35(6):615-629.

65. World Health Organization. Adolescent health. Health Topics. 2015. Retrieved from http://www.who.int/topics/adolescent_health/en/ 